\title{
An Early Risk Warning of Cross-Border E-Commerce Using BP Neural Network
}

\author{
Zhichao Deng $\mathbb{D}^{1}{ }^{1}$ Meiji Yan, ${ }^{1}$ and Xu Xiao ${ }^{2}$ \\ ${ }^{1}$ Guangzhou Panyu Polytechnic, No. 1342 Shiliang Road, Panyu, Guangdong, China \\ ${ }^{2}$ Zhejiang Vocational College of Finance, 118 Xueyuan Street, Xiasha Higher Education Park, Hangzhou, \\ Zhejiang Province, China \\ Correspondence should be addressed to Zhichao Deng; txeb@hcnu.edu.cn
}

Received 8 February 2021; Revised 1 March 2021; Accepted 10 March 2021; Published 30 March 2021

Academic Editor: Mian Ahmad Jan

Copyright (c) 2021 Zhichao Deng et al. This is an open access article distributed under the Creative Commons Attribution License, which permits unrestricted use, distribution, and reproduction in any medium, provided the original work is properly cited.

In this paper, we propose an early warning model of credit risk for cross-border e-commerce. Our proposed model, i.e., KPCAMPSO-BP, is constructed using kernel principal component analysis (KPCA), improved particle swarm optimization (IPSO), and BP neural network. Initially, we use KPCA to reduce the credit risk index for cross-border e-commerce. Next, the inertia weight and threshold of BP neural network are searched using MPSO. Finally, BP neural network is used for training the data of 13 different enterprises of cross-border e-commerce's credit risk. To analyze the efficiency of our proposed approach, we use the data of five different enterprises for testing and evaluation. The experimental results show that the mean absolute error (MAE) and root mean square error (RMSE) of our model are the lowest in comparison to the existing models and have much better efficiency.

\section{Introduction}

According to the Wall Street Journal, on September 22, 2014, Alibaba, the giant of cross-border e-commerce $[1,2]$ was listed as the largest IPO ever with a financing amount of 25 billion USD. Though this achievement was mainly due to the development of cross-border e-commerce applications, the credit risk still exists for these applications. To understand this risk, various studies have been conducted in this context. However, there exists little research when it comes to early warning of credit risk for cross-border e-commerce applications. Based on the risk level, the early warning of credit risk for these applications can be divided into four levels. Among these levels, level 1 represents the lowest risk and level 4 represents the highest risk. During cross-border e-commerce transactions, it is always desirable to select enterprises having better performance for transactions, though the credit risk level of cross-border e-commerce is always dynamic. Selecting an enterprise with better credit among various cross-border e-commerce enterprises for transactions is a major challenge that needs to be studied in detail [3]. Distinguishing the risk level of these enterprises is one of the main reasons that have made this selection quite cumbersome.

In literature, there exist very few studies for early warning of credit risk for cross-border e-commerce. For example, the authors of $[4,5]$ used the least squares approximate support vector regression model to study early warning for cross-border e-commerce credit risk. In [6-8], the authors employed the Z-score model to analyze the early warning and attained relatively better results. In [9], BP neural network was used to study the early warning of crossborder e-commerce credit risk. From the aforementioned studies, numerous factors were derived that have a direct impact on the credit risk for cross-border e-commerce applications.

In this context, using the financial information disclosed for cross-border e-commerce by listed companies and selecting better and reliable enterprises for conducting research on credit risk seems a viable option. However, there are two main challenges associated with it [10]. First, due to the larger number of financial indicators of listed enterprises, some researchers mainly focused on using the principal component analysis (PCA) for the reduction of 
dimensions, but PCA is used for dimension reduction using linear transformation, which is not effective for solving nonlinear problems. There are some nonlinear problems in the credit risk indicators of cross-border e-commerce, which have been proved by previous studies [11]. In this context, neural network seems a much better option but it has few main drawbacks associated with it such as overfitting, poorly generalized performance, and a much slower convergence speed, among others. Neural network can cooperate with PSO algorithm for determining the inertia weight and threshold of a given neural network. However, the PSO algorithm may easily fall into local minimum which ultimately leads to loss of efficiency. Besides, the results of neural network based on PSO are not accurate in most circumstances.

To solve the aforementioned problems, we use KPCA, MPSO, and BP neural network for establishing a framework for early warning of credit risk in cross-border e-commerce applications. The major contributions are as follows:

(1) Initially, the kernel principal component analysis (KPCA) is employed to solve the nonlinear feature vector extraction.

(2) Next, MPSO is used to solve the local pole problem associated with particle swarm optimization (PSO). A small value phenomenon is resolved by dynamically adjusting threshold and inertia weight for a BP neural network. Based on the principle of KPCA, MPSO, and BP neural network, this paper makes an empirical study using the credit risk's early warning of cross-border e-commerce.

The rest of this paper is organized as follows. In Section 2, we discuss our proposed combination model. In Section 3, we discuss the empirical analysis along with experimental results for our proposed model. Finally, the paper is concluded and future research directions are provided in Section 4.

\section{Combination Model}

In this section, first we discuss the principle of KPCA in Section 2.1. Next, we discuss the principle of MPSO in Section 2.2 followed by the operational principle of BP algorithm in Section 2.3. Finally, we discuss our proposed combination model in Section 2.4.

2.1. Principle of KPCA. KPCA is a multivariate statistical analysis technique that uses a kernel method by applying it to PCA. It maps multiple variables to a high-dimensional feature space via nonlinear mapping, and conducts analysis in a high-dimensional space. Based on ensuring that the relationship between the relevant variables remains unchanged, it strives to minimize the loss of original data information and reduces the credit risk index of crossborder e-commerce. Several main indexes that can reflect the characteristics of the original problem are obtained for this purpose [10-12]. KPCA is a nonlinear feature extraction method, but it has not been applied to the credit risk early warning of cross-border e-commerce. It avoids the complex problem of solving eigenvectors in eigenspace and is realized by solving eigenvectors and eigenvalues of the kernel matrix.

Firstly, for a given cross-border e-commerce credit risk sample, $x_{i}\left(i=1,2, \ldots, n, x_{i} \in R^{n}\right)$ is mapped to the feature space $H^{D}$, where $H^{D}$ is a nonlinear mapping, then the covariance matrix $C$ of the feature space $\phi(\cdot)$ sample is

$$
C=\frac{1}{N} \sum_{i=i}^{N} \phi\left(x_{i}\right)^{T} .
$$

In equation (1), the eigenvalue of $\mathrm{C}$ is decomposed into

$$
\lambda V=C V .
$$

In this equation, $\lambda(\lambda \geq 0)$ is the eigenvalue of matrix $C$ and $V$ is the eigenvector corresponding to $\lambda$. Since, $V$ is a linear combination of $\phi\left(x_{i}\right), \phi\left(x_{2}\right), \ldots \phi\left(x_{n}\right)$, then there exists $\alpha_{i}(i=1,2, \ldots, n)$.

$$
V=\sum_{i=1}^{n} \alpha_{i} \phi\left(x_{i}\right) .
$$

In equation (3), $V$ belongs to the mapping function $\phi\left(x_{t}\right)(i=1,2, \ldots, n)$ of the characteristic space $H^{D}$; the generating space is

$$
\lambda \phi^{T}\left(x_{i}\right) \quad V=\phi^{T}\left(x_{i}\right) C V, \quad i=1,2, \ldots, n .
$$

In equation (4), the matrix $K_{i, j}$ defining $n \times n$ has

$$
K=\left(k_{i j}\right)=K\left(x_{i}, x_{j}\right)=\left(\phi^{T}\left(x_{i}\right) \phi\left(x_{j}\right)\right) .
$$

In equation (5), the eigenvalue problem of $i, j=1,2, \ldots, n, \alpha_{i}$ depends on the kernel function $K_{i j}, K$ is a dot product kernel matrix, and equation (5) can be written as

$$
K \alpha=n \lambda \alpha \text {. }
$$

In equation (6), for the kernel principal component extraction of cross-border e-commerce credit risk data, the projection $P(t)$ of test set $t$ in the direction of feature space vector $V_{l}$ is calculated as follows:

$$
\begin{aligned}
P(t) & =V_{l} \phi(t)=\sum_{i=1}^{n} \alpha_{l, i}\left(\phi^{T}\left(x_{i}\right) \phi(t)\right) \\
& =\sum_{i=1}^{n} \alpha_{i, j} a K\left(x_{i}, t\right), \quad l=1,2, \ldots q .
\end{aligned}
$$

In equation (7), it has been assumed that the training set satisfies equation (1) in the feature space, $\sum_{i=1}^{n} \phi\left(x_{i}\right)=0$, and it is extremely difficult to satisfy equation (1) in the feature space. To relax the assumption $\sum_{i=1}^{n} \phi\left(x_{i}\right)=0$, the matrix expression $\left(I_{n}\right)_{i j}=(1 / n)$ is introduced, and the kernel matrix is replaced by the following form:

$$
\bar{K}=K-I_{n} K-K I_{n}+I_{n} K I_{n} .
$$

In equation (8), the maximum number of principal components extracted by KPCA is $n$. If the first few feature vectors can reflect all the characteristics of cross-border e-commerce credit risk, the number of principal components extracted can be reduced [13-15]. 
2.2. Principle of MPSO. Particle swarm optimization (PSO) is an intelligent algorithm inspired from the natural social behavior of fish and birds. In PSO, each "particle" reflects an entity that can be compared to a bird within a search space. The particle is used for solving the optimization problems. Each particle can search, follow, and memorize the current optimal particle within a solution space. The particle has a fitness value, which is determined by an optimization function and a speed that determines its flight direction and distance [16, 17]. Finally, a PSO algorithm finds the optimal solution via iterations. At first, it is initialized as a group of random particles. Particles chase two extremums and update their position in each iteration. One is the global extremum best, which is the optimal solution currently found by the whole group, and the other is the individual extremum best, which is the current optimal solution found by the particles themselves. When the fitness value of this time (current time) is equal to that of the previous time, the PSO will fall into the local minimum. To solve the abovementioned problem, PSO is improved by dynamically adjusting the weight of inertia. When the fitness value of this time is equal to the fitness value of the previous time, the particle swarm will fall into a local minimum. It can be predicted that in all future iterations if the inertia weight is equal, it is impossible to generate such an equal inertia weight. If the number of subsequent iterations is the best fitness value of the inertia weight generated by the current iteration, the inertia weight will inevitably change, and the change is irreversible, which makes PSO fall into the state of local extremum. The improvement method of PSO is introduced below. In the past, some improved algorithms for inertia weight were proposed based on equation (9). The improved inertia weight has serious disadvantages, and the improvement depends on the current iteration times and the maximum iteration times of the algorithm, which will make it fall into a local minimum. Because of these shortcomings, this paper proposes an algorithm to dynamically adjust the inertia weight, i.e., the method of first increasing and then decreasing controlled by the algorithm itself to improve the PSO algorithm $[18,19]$.

$$
\omega=\omega_{\max }-\frac{\omega_{\max }-\omega_{\min }}{\text { iter }_{\max }} \times \text { iter } .
$$

In equation (9), iter is the current number of iterations, iter $_{\max }$ is the maximum number of iterations, $\omega_{\min }$ is the minimum value of inertia weight, and $\omega_{\max }$ is the maximum inertia weight. The basic idea is as follows: using a dynamic inertia adjustment strategy, first select the inertia weight of particles with the smaller initial value, so that the initial development ability of particles is stronger. If the fitness value $f_{t-1}$ of the previous iteration is compared with the fitness value $f_{t}$ of the current iteration, the particle will fall into the local minimum at two fitness values $f=f_{t-1}$. To enhance the global search ability of particles, we can call the linear function: $\omega=\omega+\alpha \times \omega$, where $\alpha$ is a local random number in the interval (0-1), adjust the size of inertia weight, and increase the inertia weight of particles, and particles can jump out of the local extreme point. When the inertia weight increases to 1.4, the exploration ability among particles is the strongest, but the connection between particles is the weakest, i.e., the development ability of particles is the weakest. To enhance the connection between particles, a linear function, $\omega=\omega+\alpha \times \omega$, is used. Here, a local random number in the (0-1) interval is used to linearly reduce the inertia weight to enhance the connection between particles. This method is repeatedly used to make the particles control and adjust the inertia weight dynamically, and the connection of particles is developed in the direction of enhancement so that the exploration ability and development ability of particles can reach the dynamic strategic balance. The adjustment formula of inertia weight is as follows:

$$
\omega=\left\{\begin{array}{lll}
\omega+\alpha \times \omega, & f_{t}=f_{t-1} \text { and }, & \omega<1.4, \\
\omega-\alpha \times \omega, & f_{t}=f_{t-i}, & \omega \geq 1.4, \\
\omega, & f \neq f_{t-1}, &
\end{array}\right.
$$

In this equation, $\alpha$ is a random number between 0 and 1 , $\omega$ is a linear function, $f_{t}$ is the fitness value of generation $t$, and $f_{t-1}$ is the fitness value of generation $t-1$. The dynamic balance between global search and local search of particle swarm optimization is represented by the above equation [20-23].

2.3. BP Algorithm Principle. BP neural network is a predominant artificial neural network (ANN). It comprises an input layer, several hidden layers, and an output layer that has several nodes. Each node reflects a neuron, the lower and the upper nodes are connected through weights. The nodes between layers are fully interconnected, and there exists no connection among the nodes at each layer. A typical case of BP neural network is a three-layer structure network model with a hidden layer, as shown in Figure 1.

In an $\mathrm{NN}$ model, the relationship between an output $y_{t}$ and input $y_{t-1}, y_{t-2}, \ldots, y_{t-p}$ can be expressed using the following equation:

$$
y_{t}=\omega_{0}+\sum_{j=1}^{n} \omega_{j} g\left(\omega_{0_{j}}+\sum_{i=1}^{m} \omega_{i j} y_{t-i}\right)+\varepsilon_{i} .
$$

In this equation, $\omega_{i j}=(i=1,2, \ldots, n)$ and $\omega_{j}(i=1,2, \ldots, n)$ are model parameters, $n$ denotes the number of nodes at the hidden layer, $m$ reflects the number of nodes at the model input layer, and $g$ is a conversion function. The commonly used function is $g(x)=\left(1 / 1+e^{-x}\right)$.

BP neural network model described in equation (11) reflects the linear function mapping relationship between the input and output $y_{t}$ of the previous observation value of the sequence

$$
y_{t}=f\left(y_{t-1}, y_{t-2}, \ldots, y_{t-p}, \omega\right)+\varepsilon_{t} .
$$




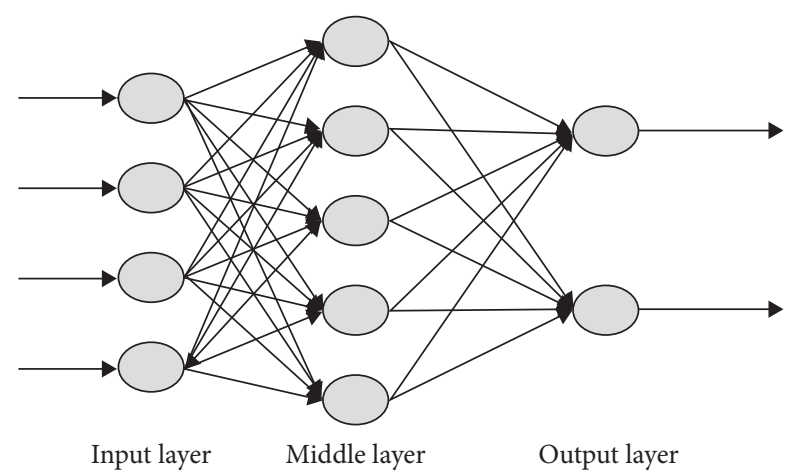

FIgURE 1: Structure of BP neural network model.

In equation (12), $\omega$ is the parameter vector of all models; function $f(\cdot)$ is determined by network structure and weight parameters [24, 25], respectively.

2.4. Combination Model. Our combination model, i.e., KPCA-MPSO-BP, is discussed in detail here. The basic idea of this model is as follows: firstly, the eigenvalues and eigenvectors of the indicators of cross-border e-commerce credit risk are calculated. Then, the kernel principal component eigenvectors with cumulative contribution rate greater than $85 \%$ are calculated, and finally, MPSO is used to search the weights and thresholds of BP neural network. The current position and fitness of the particles in the swarm are expressed by the weights, thresholds, and errors of the BP neural network and the results are compared. To analyze whether or not to update the PSO algorithm, BP neural network is used for early warning calculation. The flowchart of our proposed model is shown in Figure 2.

The operation steps of our model are as follows:

(1) Data collection and data preprocessing:

The credit risk indicators of cross-border e-commerce are standardized, and the reverse indicators are converted into positive indicators. The method is 1 -index value, that is, $x_{i j}=1-x_{i j}$, where $x_{i j}$ is the reverse index and $x_{i j}$ is the positive index after conversion. The formula of normalization is as follows:

$$
x_{i j}^{\prime \prime}=\frac{x_{i j}-x_{\min }}{x_{\max }-x_{\min }} .
$$

(2) Calculate the kernel matrix:

After data standardization, the cross-border e-commerce credit risk data is analyzed by KPCA, and the eigenvalues and eigenvectors of covariance are calculated.

(3) Feature values extraction:

KPCA method is used to reduce the dimension of the input eigenvalue. The standard of dimension reduction is to select the kernel principal component eigenvector which contains more than $85 \%$ information.
(4) Initialize PSO:

Initialize the initial position and initial velocity of the population, set the minimum fitness value as $\varepsilon$ and the maximum number of iterations as $m$, and transfer the initial position of particles to the initial optimal position of particles.

(5) BP neural network initialization:

The initial position of particles is transferred to BP neural network as the initial threshold and initial value of the BP neural network.

(6) Output and average error:

The output and average error $\varepsilon_{1}=\left(1 / 1+e^{-x}\right)$ of the BP neural network are calculated. The comprehensive score of sample data is taken as the expected output value, the average error of the BP neural network is calculated, the fitness value of particle swarm optimization algorithm is determined by the network error $\varepsilon t$, and the fitness value of particle swarm optimization algorithm is determined [6].

(7) Training set of BP neural network:

Part of the data of cross-border e-commerce credit risk is taken as the training set of BP neural network, and the training calculation is carried out in the network.

(8) Test set of BP network:

Another part of the data of cross-border e-commerce credit risk is taken as the test set of BP neural network and tested in BP neural network.

(9) Credit warning:

According to the score of the BP neural network, the credit warning of cross-border e-commerce enterprises is carried out. Based on the results of test/inspection, the credit risk of cross-border e-commerce enterprises is given early warning according to the risk level.

(10) Error analysis:

To test the superiority of the KPCA-MPSO-BP model, mean absolute percentage error (MAPE) and root mean square error (RMSE) are calculated. These two metrics are used for error analysis:

$$
\text { MAPE }=\frac{1}{n} \sum_{i=1}^{n}\left|\frac{x_{i}-\tilde{x}_{i}}{x_{k}}\right| \times 100 \%,
$$

$$
\mathrm{RMSE}=\sqrt{\frac{\sum_{i=1}^{n}\left(x_{i}-\hat{x}_{i}\right)^{2}}{n}} .
$$

In equations (14) and (15), smaller the mean absolute error and root mean square error, the better will be the results.

\section{Empirical Analysis}

According to the characteristics of cross-border e-commerce credit risk enterprises, data sources use the index system of 


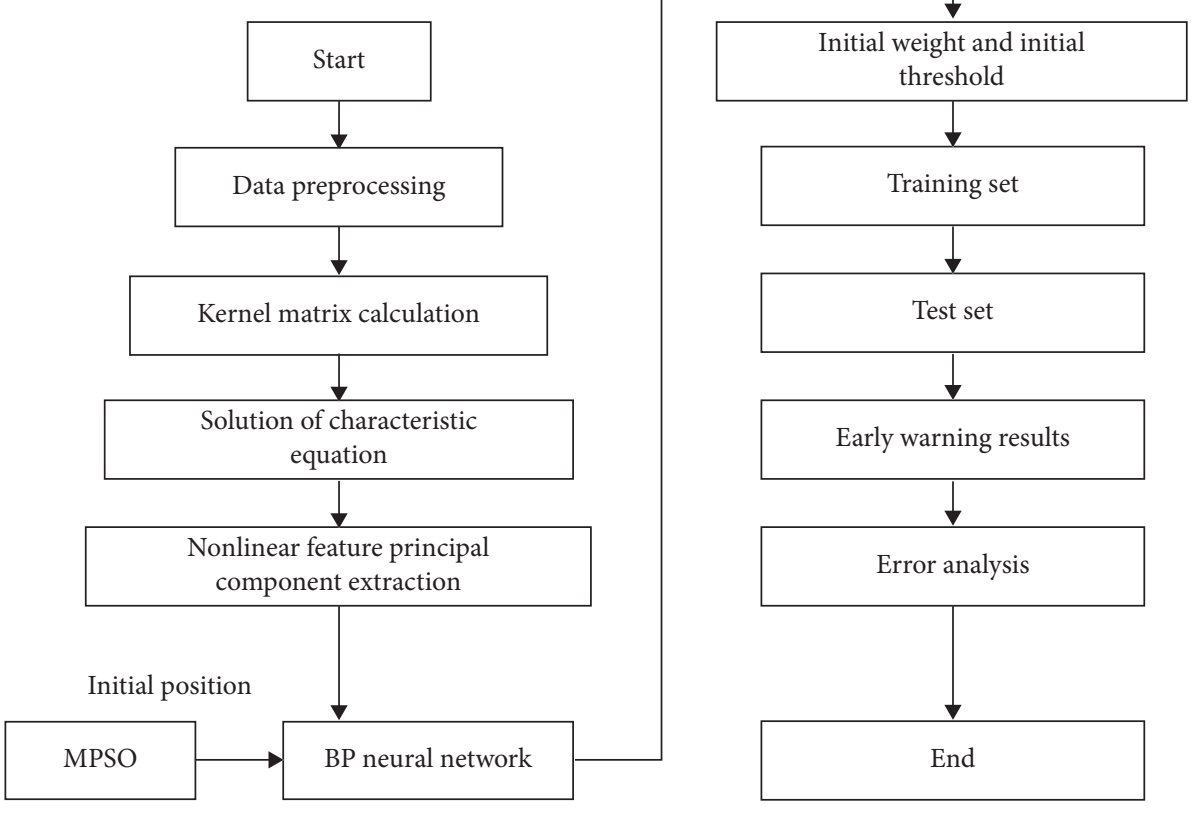

FIGURE 2: Flowchart of the combination model.

$[1,3]$ to make an empirical study on cross-border e-commerce credit risk.

3.1. Selection of Research Samples and Indicators. Taking the data of 18 international cross-border e-commerce enterprises as the sample, the selected indicators for our studies are sales profit rate $X_{1}$, return on net assets $X_{2}$, return on total assets $\mathrm{X}_{3}$, total assets turnover $\mathrm{X}_{4}$, cost and expense profit rate $\mathrm{X} 5$, inventory turnover $\mathrm{X}_{6}$, accounts receivable turnover $\mathrm{X}_{7}$, current assets turnover $\mathrm{X}_{8}$, interest multiple $\mathrm{X}_{9}$, digital certificate grade $\mathrm{X}_{10}$, quick ratio $\mathrm{X}_{11}$, current ratio $\mathrm{X}_{12}$, capital accumulation rate $\mathrm{X}_{13}$, platform service provider credit $\mathrm{X}_{14}$, fixed assets renewal rate $\mathrm{X}_{15}$, total assets growth rate $\mathrm{X}_{16}$, contract breaking rate $\mathrm{X}_{17}$, overdue payment rate $\mathrm{X}_{18}$, and trade volume growth rate $\mathrm{X}_{19}$. The 18 enterprises are named enterprise $A$, enterprise $B$, and enterprise $R$, respectively. The index meanings are shown in Table 1.

According to the definition of Table 1, the original data in Table 2 can be obtained by using the data in [3].

3.2. Data Processing. According to the combination processing method in Section 2.4, the standardized transformation of the original data (including the normalization of the reverse index into the positive index) enables the standardized cross-border e-commerce credit risk matrix. We adopt KPCA standard of the dimension reduction for selecting the cumulative contribution rate of the eigenvalue, which accounts for $85 \%$. The initial position of the particle is transferred to BP neural network as the initial threshold and initial value of the BP neural network. First, 13 groups of data are used to form the training set, then the BP neural network is used to train, and then the other 5 groups of data are used to form the test set. Using the prediction test, the credit risk of cross-border e-commerce is divided into four categories: level 1 risk (80100), level 2 risk [60, 80], level 3 risk $[30,60]$, and level 4 risk $[0,30]$. Among them, level 1 and level 2 are in a risk state, while level 3 and level 4 are in a riskfree state. If the score is greater than or equal to 60 , it is no alarm, and if the score is less than 60, it is an alarm. The data after standardized processing are shown in Table 3.

3.3. Credit Risk Early Warning Analysis of Cross-Border E-Commerce. According to the early warning of crossborder e-commerce credit risk in Table 3, enterprises are classified, as shown in Table 4.

As can be seen from Table 4 , there are 4 enterprises in good condition (level 1 risk). These enterprises include $\mathrm{D}, \mathrm{E}$, $\mathrm{I}$, and $\mathrm{P}$, respectively. These enterprises are in good financial condition. Next, there are 6 enterprises in Level 2 risk (normal condition) that include A, G, I, K, N, and Q, respectively. The financial status of these enterprises is good and there is no credit risk. There are 5 enterprises with level 3 risk (slight risk). The financial status of the cross-border e-commerce enterprises in this section is not very good, with slight credit risk. Finally, there are 3 enterprises with grade 4 risk (serious risk), including J, F, and $\mathrm{O}$ as the table shows. The financial status of the enterprises in this section is extremely dangerous, with a relatively serious credit crisis.

3.4. Model Combination Fitting Test. For the test of the model, the average absolute error and root mean square error of the model can be compared by BP, PSO-BP, MPSO$\mathrm{BP}$, and KPCA-MPSO-BP, as shown in Table 5. 
TABLE 1: The meaning of credit risk early warning in cross-border e-commerce.

\begin{tabular}{|c|c|c|}
\hline $\begin{array}{l}\text { Serial } \\
\text { number }\end{array}$ & Index name & Indicator meaning \\
\hline 1 & Sales profit margin $\mathrm{X}_{1}$ & Sales profit rate $=$ total profit $/$ net sales revenue \\
\hline 2 & Return on equity $\mathrm{X}_{2}$ & Return on net assets $=$ net profit/average balance of owner's equity \\
\hline 3 & Return on total assets $\mathrm{X}_{3}$ & Return on total assets $=$ profit before interest and tax/average balance of total assets \\
\hline 4 & Total assets turnover rate $\mathrm{X}_{4}$ & The turnover rate of total assets = net income of main business/average balance of total assets \\
\hline 5 & Cost profit margin $\mathrm{X}_{5}$ & Cost profit rate $=$ total profit $/$ total cost \\
\hline 6 & Inventory turnover rate $\mathrm{X}_{6}$ & Inventory turnover rate $=$ inventory turnover times $=$ cost of goods sold/average inventory \\
\hline 7 & $\begin{array}{l}\text { Accounts receivable turnover } \\
\text { rate } \mathrm{X}_{7}\end{array}$ & $\begin{array}{l}\text { The turnover rate of accounts receivable }=\text { net income of main business/average balance of } \\
\text { accounts receivable }\end{array}$ \\
\hline 8 & $\begin{array}{l}\text { Current assets turnover rate } \\
\qquad \mathrm{X}_{8}\end{array}$ & $\begin{array}{c}\text { The turnover rate of current assets }=\text { net income of main business/average balance of current } \\
\text { assets }\end{array}$ \\
\hline 9 & Interest multiple $\mathrm{X}_{9}$ & Multiple of interest earned $=$ profit before interest and tax/interest expense \\
\hline 10 & Level of digital certificate $\mathrm{X}_{10}$ & $\begin{array}{c}\text { Digital certificate is divided into five levels, corresponding to the score, it's } 1.0,0.80,0.60,0.40 \text {, } \\
\text { and } 0.20\end{array}$ \\
\hline 11 & Quick ratio $\mathrm{X}_{11}$ & Quick ratio $=($ current assets inventory $) /$ current liabilities \\
\hline 12 & io $\mathrm{X}_{12}$ & Current ratio $=$ current assets/currer \\
\hline 13 & $\begin{array}{l}\text { Capital accumulation rate } \\
\qquad \mathrm{X}_{13}\end{array}$ & $\begin{array}{c}\text { Capital accumulation rate }=\text { growth of owner's equity in the current year/beginning of the } \\
\text { year owner's equity }\end{array}$ \\
\hline 14 & $\begin{array}{l}\text { Platform service provider } \\
\text { credit X14 }\end{array}$ & $\begin{array}{l}\text { According to the degree of recognition, it is divided into five levels, and the corresponding } \\
\text { scores } 0.80,0.60,0.40,0.20 \text {, and } 0\end{array}$ \\
\hline 15 & $\begin{array}{l}\text { The renewal rate of fixed } \\
\text { assets } \mathrm{X}_{15}\end{array}$ & The update rate of fixed assets = original value of new fixed assets/period end fixed assets \\
\hline 16 & $\begin{array}{l}\text { The growth rate of total assets } \\
\qquad \mathrm{X}_{16}\end{array}$ & $\begin{array}{c}\text { The growth rate of total assets }=\text { growth amount of total assets in this year/capital at the } \\
\text { beginning of the year. Total output } \times 100 \%\end{array}$ \\
\hline 17 & Contract breaking rate $\mathrm{X}_{17}$ & $\begin{array}{c}\text { Breach rate }=\text { total amount of breach contract/total amount of signed contract amount of } \\
\text { money }\end{array}$ \\
\hline 18 & Overdue payment rate $\mathrm{X}_{18}$ & $\begin{array}{c}\text { Overdue loan rate }=\text { total number of days beyond the repayment period/total number of days } \\
\text { of loan total days }\end{array}$ \\
\hline 19 & $\begin{array}{l}\text { The growth rate of trade } \\
\text { volume } \mathrm{X}_{19}\end{array}$ & $\begin{array}{c}\text { The growth rate of trade volume }=\text { trade growth of this year/total trade of this year exchange } \\
\text { amount }\end{array}$ \\
\hline
\end{tabular}

TABle 2: Credit risk data of 18 enterprises.

\begin{tabular}{lcccccccccc}
\hline On & Name & $\mathrm{X}_{1}$ & $\mathrm{X}_{2}$ & $\mathrm{X}_{3}$ & $\mathrm{X}_{4}$ & $\mathrm{X}_{5}$ & $\ldots$ & $\mathrm{X}_{17}$ & $\mathrm{X}_{18}$ & $\mathrm{X}_{19}$ \\
\hline 1 & A enterprise & 0.362 & 0.362 & 0.293 & 1.263 & 1.235 & $\ldots$ & 0.068 & 0.368 & 0.259 \\
2 & B enterprise & 0.282 & -0.523 & -0.453 & 1.326 & 0.686 & $\ldots$ & 0.089 & 0.319 & 0.688 \\
3 & C enterprise & -0.342 & 0.395 & 0.264 & 0.984 & 1.267 & $\ldots$ & 0.037 & 0.287 & 0.577 \\
4 & D enterprise & 0.293 & 0.457 & 0.165 & 0.885 & 2.368 & $\ldots$ & 0.125 & 0.105 & 0.496 \\
5 & E enterprise & 0.146 & -0.298 & -0.217 & 1.368 & 0.889 & $\ldots$ & 0.053 & 0.396 & -0.285 \\
6 & F enterprise & -0.413 & 0.372 & 0.648 & 1.529 & 0.984 & $\ldots$ & 0.015 & 0.687 & -0.052 \\
7 & G enterprise & 0.374 & 0.254 & 0.539 & 0.997 & 5.235 & $\ldots$ & 0.076 & 0.758 & 0.373 \\
8 & H enterprise & 0.355 & -0.166 & -0.391 & 1.682 & 0.686 & $\ldots$ & 0.037 & 0.499 & 0.496 \\
9 & I enterprise & 0.217 & 0.195 & 0.342 & 2.015 & 4.267 & $\ldots$ & 0.119 & 0.852 & 0.278 \\
10 & J enterprise & 0.258 & 0.183 & 0.503 & 1.354 & 5.212 & $\ldots$ & 0.122 & 0.463 \\
11 & K enterprise & -0.499 & -0.287 & -0.185 & 0.896 & 0.893 & $\ldots$ & 0.034 & 0.644 & -0.299 \\
12 & L enterprise & 0.642 & 0.391 & 0.187 & 1.364 & 4.374 & $\ldots$ & 0.075 & 0.595 \\
13 & M enterprise & 0.571 & 0.388 & 0.268 & 1.093 & 2.675 & $\ldots$ & 0.057 & 0.476 \\
14 & N enterprise & 0.393 & -0.427 & -0.329 & 0.855 & 0.978 & $\ldots$ & 0.069 & 0.317 & -0.197 \\
15 & O enterprise & -0.132 & 0.193 & 0.196 & 2.995 & 1.684 & $\ldots$ & 0.064 & 0.272 \\
16 & P enterprise & 0.095 & 0.487 & 0.115 & 2.687 & 3.565 & $\ldots$ & 0.126 & 0.194 & 0.241 \\
17 & Q enterprise & 0.284 & -0.448 & -0.384 & 0.974 & 0.886 & $\ldots$ & 0.113 & 0.241 & 0.386 \\
18 & R enterprise & 0.487 & 0.435 & 0.357 & 2.686 & 2.988 & $\ldots$ & 0.087 & 0.353 & 0.545 \\
\hline
\end{tabular}

It can be seen from Table 5 that the RMSE and MAPE of the KPCA-MPSO-BP model are the smallest, which indicates that the KPCA-MPSO-BP model has higher early warning accuracy than the single model, the MPSO-BP model has higher early warning accuracy than the PSO-BP model, and KPCA-MPSO-BP model has the highest early warning accuracy, which indicates that the KPCA-MPSO$\mathrm{BP}$ model has the good fitting degree and the KPCAMPSO-BP model proposed in this paper is scientific and reasonable. 
TABLE 3: Early warning table of credit risk score of BP neural network training set and test set.

\begin{tabular}{lccccccccc}
\hline Serial number & Enterprise & Score & Risk level & Is there an alarm & Serial number & Enterprise & Score & Risk level & Is there an alarm \\
\hline 1 & A & 69 & 2 & No & 10 & J & 22 & 4 & Yes \\
2 & B & 46 & 3 & Yes & 11 & K & 72 & 2 & No \\
3 & C & 45 & 3 & Yes & 12 & L & 94 & 1 & No \\
4 & D & 91 & 1 & No & 13 & M & 39 & 3 & Yes \\
5 & E & 87 & 1 & No & 14 & N & 78 & 2 & No \\
6 & F & 27 & 4 & Yes & 15 & O & 26 & 4 & Yes \\
7 & G & 78 & 2 & No & 16 & P & 89 & 1 & No \\
8 & H & 51 & 3 & Yes & 17 & Q & 76 & 2 & No \\
9 & I & 64 & 2 & No & 18 & R & 56 & 3 & Yes \\
\hline
\end{tabular}

TABLE 4: Cross-border e-commerce credit risk early warning table.

\begin{tabular}{lcccc}
\hline Category & Level 1 risk (no alarm) & Level 2 risk (no alarm) & Level 3 risk (with alarm) & Level 4 risk (with alarm) \\
\hline & D enterprise & A enterprise & B enterprise & F enterprise \\
Enterprise name & E enterprise & G enterprise & C enterprise & J enterprise \\
& I enterprise & I enterprise & H enterprise & O enterprise \\
& P enterprise & K enterprise & M enterprise & \\
& & N enterprise & R enterprise & \\
\hline
\end{tabular}

TABle 5: Comparison of mean absolute error and root mean square error of different models.

\begin{tabular}{lccccc}
\hline $\begin{array}{l}\text { Serial } \\
\text { number }\end{array}$ & Prediction model & RMSE & Sort & MAPE (\%) & Sort \\
\hline 1 & BP & 0.2555 & 4 & 3.96 & 4 \\
2 & PSO BP & 0.1410 & 3 & 2.240 & 3 \\
3 & MPSO-BP & 0.0898 & 2 & 1.545 & 2 \\
4 & KPCA-MPSO-BP & 0.0377 & 1 & 1.018 & 1 \\
\hline
\end{tabular}

\section{Conclusion}

To improve the ability to prevent the credit risk of crossborder e-commerce enterprises, this paper proposes a combination model of KPCA-MPSO-BP. This model is used to early warn the credit risk of cross-border e-commerce enterprises and analyze the relevant sample data. The results show that the KPCA-MPSO-BP combination model is effective in early warning for any credit risk. Compared with other models, KPCA-MPSO-BP has fewer parameters, faster calculation speed, and better fitting. Though our model has much better results, there is still room for improvement. For example, for enterprises with grade 1 risk (excellent state), there is no credit risk, so it is necessary to strengthen the data collection of credit rating to avoid the occurrence of credit risk. For the enterprises in the level 2 risk (normal state), there is a possibility of credit risk, hence we should strengthen the analysis of the potential factors of credit risk, strengthen the management, and prevent the occurrence of credit risk. For enterprises with level 3 risks (slight risk status), if there is a slight risk and they are in early warning status, we should strengthen the work of enterprise credit risk, improve the credit, and reduce the occurrence of credit risk. The enterprises with level 4 risk (serious risk status) are in the early warning status and have serious credit risk, so they should stop business, strengthen rectification and clean-up, and enter the risk plan procedure to prevent the occurrence of enterprise bankruptcy.

\section{Data Availability}

The data used to support the findings of this study are included within the article.

\section{Conflicts of Interest}

The authors declare that they have no conflicts of interest.

\section{References}

[1] S. Xie, "Prediction of repeat purchase customers in e-commerce platform based on the neural network," Journal of Changchun Institute of Technology (Natural Science Edition), vol. 21, no. 1, pp. 97-100, 2020.

[2] H. Wang, "An e-commerce satisfaction evaluation method based on deep learning," Electronic Devices, vol. 43, no. 1, pp. 196-199, 2020.

[3] Z. Xiao, Research on Trust Evaluation of Social E-Commerce Based on BP Neural Network, Shenyang University of Technology, Shenyang, China, 2020.

[4] Y. Cao, Research on Conversational Recommendation System Based on the Neural Network, Zhejiang University, Hangzhou, China, 2020.

[5] Y. Zhou, Research on Sentiment Analysis of Commodity Reviews Based on the Convolutional Neural Network, Nanjing University of Posts and telecommunications, Nanjing, China, 2019.

[6] Y. Wan and Y. Zhang, "Research on abnormal transaction data detection based on the probabilistic neural network," Communication World, vol. 26, no. 11, pp. 39-40, 2019.

[7] C. Yi, Research on Garment Image Retrieval Technology Based on the Convolutional Neural Network, Zhejiang University of Technology, Hangzhou, China, 2020. 
[8] G. C. Yin, Research on Clothing Style Recognition and Recommendation Based on the Convolutional Neural Network, Zhejiang University of Technology, Hangzhou, China, 2020.

[9] Y. Mao, Research on Recommendation Algorithm Based on the Convolutional Neural Network, West China Normal University, Nanchong, China, 2019.

[10] J. Chen, Research and Implementation of Commodity Recommendation System Based on the Neural Network, University of Electronic Science and Technology, Chengdu, China, 2019.

[11] G. Yang and B. Guo, "User behavior prediction of e-commerce platform enhanced by machine learning," Science and Technology and Innovation, vol. 3, no. 1, pp. 124-125, 2019.

[12] L. Wang, E-commerce Image Text Detection and Recognition Based on Deep Learning, Wuhan Research Institute of Posts and Telecommunications, Wuhan, China, 2019.

[13] Z. Kang, Research on Cross Border E-Commerce Logistics Risk Evaluation Based on the Genetic Neural Network, Chang'an University, Xi'an, China, 2018.

[14] W. Yang, Research and Application of Collaborative Filtering Recommendation Algorithm Based on BP Neural Network, Wuhan Research Institute of Posts and Telecommunications, Wuhan, China, 2018.

[15] H. Zhang, "Analysis of data mining technology in e-commerce network marketing," Journal of Chifeng University (Natural Science Edition), vol. 33, no. 21, pp. 90-91, 2017.

[16] H. Wang, "Logistics demand forecast of Hangzhou metropolitan area based on BP neural network," Modern Commerce and Trade Industry, vol. 29, pp. 46-47, 2017.

[17] W. Shi and X. Wang, "Research on E-commerce credit evaluation model based on clustering and BP neural network," Fujian Computer, vol. 33, no. 8, pp. 1-4 +20, 2017.

[18] C. Yao, H. Shan, H. Hu, and D. Gao, "Risk assessment of cross border e-commerce logistics based on BP neural network," Economic Research Guide, vol. 22, pp. 157-159, 2017.

[19] K. Zhou, Research on Enterprise E-Commerce Credit Risk Early Warning Based on Bagging Method, Guangxi University, Nanning, China, 2017.

[20] M. Qian, Repeat Purchase Customer Prediction of E-Commerce Platform Based on Machine Learning, Lanzhou University, Lanzhou, China, 2017.

[21] K. Zhao, E-commerce Data Deep Mining Based on the Convolutional Neural Network, Zhejiang University, Hangzhou, China, 2017.

[22] Y. Huang, Design and Implementation of E-Commerce Customer Segmentation System Based on Cluster Analysis, Jiangsu University of Science and Technology, Zhenjiang, China, 2016.

[23] Y. Tang, Research on Recommendation Algorithm Based on User Behavior in E-Commerce, Hunan University, Changsha, China, 2016.

[24] X. Lian, Research on Recommendation Algorithm Based on Sorting Learning and Convolutional Neural Network, Dalian University of Technology, Dalian, China, 2016.

[25] J. Wu and X. Zhou, "E-commerce credit risk early warning based on KPCA and BP neural network," Logistics Technology, vol. 35, no. 4, pp. 97-102, 2016. 